\title{
Relay Cropping Bell Pepper and Tomato: Effects of Cropping Sequence and Transplanting Date
}

\author{
Ravneet K. Sandhu and Nathan S. Boyd \\ Gulf Coast Research and Education Center, University of Florida, Balm, \\ FL 33598
}

\section{Lincoln Zotarelli \\ Department of Horticultural Sciences, University of Florida, Gainesville, FL 32611}

\section{Shinsuke Agehara and Natalia Peres \\ Gulf Coast Research and Education Center, University of Florida, Balm, FL 33598}

Additional index words. competition, Florida, plant interactions, shading, vegetable production

\begin{abstract}
Vegetable growers in Florida face rising production costs, reduced crop value, and competition from foreign markets. Relay cropping is a variant of double cropping, where the second crop is planted into the first crop before the harvest is finished. This cropping system may be a potential solution to lower production costs per crop by sharing some inputs for two crops. The objectives of this study were to determine the effect of cropping sequence and transplanting date of the secondary crop when relay cropping tomato and bell pepper. Two field experiments were conducted at the Gulf Coast Research and Education Center in Balm, FL, in 2018 and 2019. In the first experiment, tomato was grown as the primary crop and bell pepper was added as the secondary crop, with multiple transplanting dates (8 Aug., 23 Aug., 7 Sept., and 24 Sept.). The second experiment had the same setup but the reverse cropping sequence. Bell pepper yield as the secondary crop was reduced by $65 \%$ when grown with tomato as the primary crop compared with bell pepper planted alone. Transplanting date had no effect on bell pepper yield $(P=0.091)$. Tomato yield was unaffected by the presence of the secondary crop. In the second experiment, tomato yield as a secondary crop was $36 \%$ lower when grown with bell pepper as the primary crop compared with tomato crop alone (monocropped). However, tomato yield was significantly reduced by the presence of bell pepper only when tomato crop was planted within 30 to 45 days after planting bell pepper. Based on these results, we recommend relay cropping tomato as the secondary crop within 30 days of planting of bell pepper as the primary crop. However, we do not recommend relay cropping bell pepper as the secondary crop with tomato.
\end{abstract}

Bell pepper (Capsicum annuum L.) and tomato (Solanum lycopersicum L.) are warm season vegetable crops extensively grown throughout the United States. The top three states for tomato and bell pepper production are California, Georgia, and Florida. Florida is ranked first in fresh market production.

Received for publication 20 Apr. 2021. Accepted for publication 26 May 2021.

Published online 6 July 2021.

R.K.S. is a Post-Doctoral Associate.

N.S.B. and L.Z. are Associate Professors.

S.A. is an Assistant Professor.

N.P. is a Professor of Plant Pathology.

We thank the Florida Department of Agriculture and Consumer Services for the financial support. We also thank the weed science laboratory members and farm crew members at Gulf Coast Research and Education Center, Balm, FL.

N.S.B. is the corresponding author. E-mail: nsboyd@ufl.edu.

This is an open access article distributed under the CC BY-NC-ND license (https://creativecommons. org/licenses/by-nc-nd/4.0/).
From 2000 to 2015 , the harvested acreage for tomato and bell pepper in Florida declined from 15,760 to 13,200 ha and from 7360 to 4880 ha, respectively. This represents a $40 \%$ decline in production acreage (Liu et al., 2018). In 2015 , the total bell pepper production in Florida was $\approx 0.2$ million metric tons (USDA-NASS, 2016); however, in 2000, it was 0.3 million metric tons. The rapid decline in the production area over the past few years has been caused, in part, by the banning of methyl bromide, increased competition from foreign markets, and increased production costs (Biswas et al., 2017; Guan et al., 2017).

Intercropping is one approach that may help compensate for the increased production costs associated with vegetable crops. Intercropping is a production system that is characterized by growing multiple cultivars or crop species simultaneously in the same field (spatial diversification) using some of the same resources, such as plastic mulch, drip tape, and fumigation (Duval, 2005). It is classified as mixed, relay, or strip cropping based on the production design and transplanting date (Rosa-Schleich et al., 2019). There are many other advantages of intercropping, such as an increase in the number of natural enemies through elevated flower richness, which results in reduced pest incidence as compared with monocultures (Letourneau et al., 2011). A field study conducted in Turkey reported that intercropping systems such as strawberry-onion, strawberry-radish, and strawberry-cos lettuce are known to increase the per-unit productivity and total yields without limiting the yield potential of strawberry grown as the primary crop (Karlidag and Yildirim, 2009).

Competitive interactions between plants for resources is one of the primary challenges associated with intercropping (Theunissen, 1997). However, in relay cropping systems, two or more crops are transplanted on the same bed at different times, with the planting of the second crop typically performed after the maturity of the first crop. It is likely that the degree of competition would be lower, at least in regard to the primary crop, compared with that of other intercropping systems, such as a strip of mixed intercropping. However, the secondary crop could be subjected to severe competition and subsequently have lower yields (Jacques et al., 1997). Many studies have compared relay cropping of cereal crops and grasses (Gaudin et al., 2014); however, there have been limited studies of relay cropping of vegetables such as tomato and bell pepper.

Success of a relay cropping system will rely, in part, on selecting the correct transplanting date for the secondary crop to maximize the resource use efficiency and to ensure maximum overlap of the vegetative growth phase of both plants. It is crucial to determine the degree of competition between the primary and the secondary crops, assess the competition, minimize resource use, and maximize the yield potential of both crops. Early planting of the secondary crop could result in increased competition for resources such as water, nutrients, and light. However, if it is transplanted too late, then shading from the primary crop could become a major limiting factor, particularly for crops with canopy differences. A study of relay cropping melons, squash, and cucumbers indicated that the planting date affected the yields of the crops differently when relay cropping was performed earlier or later in the season (Santos et al., 2008). The differences could be attributable to the warmer temperatures that favored the yield of summer squash; however, the opposite trend was observed for muskmelons. More recently, a series of studies of relay cropping plants such as eggplant, jalapeno pepper, and cantaloupe with strawberry demonstrated the potential of this method in Florida, and it indicated that relay cropping could be profitable for growers without the loss of yield or revenue of the strawberry crop (Sandhu et al., 2020). These studies found that the optimum transplanting date of the secondary crop varies according to the crop, and that revenue is mainly based on the yields of the crops. 
In this study, we hypothesized that tomato relay cropped with bell pepper or vice versa would reduce the yields of both crops, and the longer the competitive interval, the lower the yield. The objectives of the study were to: a) determine the optimum date and order of planting the secondary crop (either tomato or bell pepper) in a relay cropping production system, and b) determine the effects of competition between two crops on plant morphology (plant height, biomass, and stem girth) and yield.

\section{Materials and Methods}

Experimental setup. Field experiments were conducted in Fall 2018 and 2019 at the University of Florida, Gulf Coast Research and Education Center (GCREC) $\left(27^{\circ} \mathrm{N}\right.$, $\left.82^{\circ} \mathrm{W}\right)$, Balm, FL. Soil pH was 5.5 to 6.0 , with $1.5 \%$ organic matter. The soil at the site was Myakka fine sand (sandy, siliceous, hyperthermic Oxyaquic Alorthod) with a soil texture of $98 \%$ sand, $1 \%$ silt, and $1 \%$ clay. Experiments were $2 \times 4$ factorial setups in the field as a randomized complete block design with four replications. Raised beds were shaped and fumigated on 12 and 16 July 2018 and 2019, respectively, using a three-shanked fumigation rig with shanks set at $20 \mathrm{~cm}$ depth. The fumigant was Pic-Clor 60 (37.1\% 1,3-Dichloropropene and 56.7\% Chloropicrin) at $136 \mathrm{~kg} / \mathrm{ha}$ (Dow AgroSciences, Indianapolis, IN). Two drip tapes per row with emitters every $30 \mathrm{~cm}$ and a flow rate of $0.95 \mathrm{~L} \cdot \mathrm{min}^{-1} \cdot 30 \mathrm{~m}^{-1}$ ) were installed (Jain Irrigation Inc., Haines City, FL); then, beds were covered with virtually impermeable plastic mulch (Berry Plastics Corp., Evansville, IN).

Tomato with bell pepper as the secondary crop. Tomato (cv. Charger) transplants (Speedling Inc., Ruskin, FL) were transplanted with $61-\mathrm{cm}$ spacing in the center of raised plasticcovered beds on 8 and 16 Aug. 2018 and 2019 , respectively. In the experimental setup, the first factor was the presence/absence of bell pepper (secondary crop), and the second factor was the transplanting date of the bell pepper. Bell pepper (cv. Aristotle) was transplanted as the secondary crops in two parallel rows at $38 \mathrm{~cm}$ with pepper-to-pepper spacing on the same beds as the tomato. Bell pepper was transplanted on four planting dates at 15d interval (8 Aug., 23 Aug., 7 Sept., and 24 Sept.). Bell pepper was also transplanted alone using the same planting pattern on the respective dates as a control. The bell pepper transplants were grown in a greenhouse at GCREC for 6 weeks before being transplanted.

Bell pepper with tomato as the secondary crop. Six-week-old bell pepper (cv. Aristotle) transplants (Speedling Inc., Ruskin, FL) were transplanted at $38-\mathrm{cm}$ spacing between plants in two parallel rows on plastic-covered raised beds on 8 and 16 Aug. 2018 and 2019, respectively. The experimental setup was a randomized complete block design $2 \times 5$ factorial design; the first factor was the presence/absence of tomato (secondary crop) and the second factor was the date of the planting of tomato. Tomato (cv. Charger) transplants were transplanted in the center of the same beds on four different planting dates at 15-d intervals (8 Aug., 23 Aug., 7 Sept., and 24 Sept). Tomato was transplanted alone on the respective dates as the control. The planting dates of the primary and secondary crops were delayed by 1 week in 2019, and standard dates of 8 Aug., 23 Aug., 7 Sept., and 24 Sept. were used to present the results. The tomato seedlings for the various transplanting dates were raised in a greenhouse at GCREC for 6 weeks.

The planting pattern of crops on beds in each experiment was the same as reported by the previous studies (Sandhu et al., 2021). Irrigation, fertilization, disease, and pest management of tomato and bell pepper were performed according to industry recommendations (Freeman et al., 2017). The fertilizer was applied at 226-112-112 (N-P-K) kg/ha to the tomato and pepper. Irrigation was scheduled for $1 \mathrm{~h}$ twice per day.

Data collection. Plant height of the five tomato and bell pepper plants per plot was recorded every $15 \mathrm{~d}$ for 2 months. Plant shoot biomass was measured for 1- and 2-monthold tomato and bell pepper plants per plot. Two plants per plot were clipped at the soil surface and dried in an oven at $60^{\circ} \mathrm{C}$ until a uniform weight was obtained. Stem girth at the base of the plant and internode length (three internodes from the base) were measured for bell pepper plants per plot at 1 and 2 months after transplanting. Three photosynthetically active radiation measurements were performed per plot with a Line Quantum Sensor LI-191R on 14 Oct. 2018 and 2019 (LICOR Biosciences, Lincoln, NE). Because the row orientation was south-north in the experimental setup, light measurements were taken from the east and west sides of the bed to account for differences in shading over a 24-h period. Tomato and bell pepper fruits were harvested twice at 15-d intervals upon maturity. Similarly, the bell pepper weight and count were recorded. Tomato fruits were harvested and graded as small $(<58 \mathrm{~mm})$, medium (58-64 mm), large $(64-73 \mathrm{~mm})$, and extra-large $(73-88 \mathrm{~mm})$ based on the fruit size (Sargent, 1998).

Data analysis. Fruit weight, count, stem girth, and biomass data were subjected to an analysis of variance (ANOVA) using the PROC GLIMMIX procedure in SAS (version 9.4; SAS Institute, Cary, NC). The presence/ absence of bell pepper and the date of planting bell pepper were considered fixed factors in Expt. 1. The presence/absence of tomato and planting dates of tomato were considered fixed factors in Expt. 2. Replication was considered a random factor for the experiments. Mean separation was performed using Tukey's least significant difference. Plant height data were analyzed by regression using Sigma Plot ${ }^{\mathrm{TM}}$ (Systat Software Inc., San Jose, CA). The regression slopes were compared among treatments using an ANOVA.

Land equivalent ratio. Land equivalent ratio (LER) is the measure the productivity and effectiveness of intercropping. The LER is calculated by using the following formula:

$$
\begin{aligned}
\text { LER }= & \frac{\text { Yield (tom)intercropped }}{\text { Yield (tom)monocropped }} \\
& +\frac{\text { Yield (pep)intercropped }}{\text { Yield (pep)monocropped }}
\end{aligned}
$$

\section{Results}

\section{Tomato with bell pepper as the secondary crop}

Pepper biomass. The interaction among the bell pepper transplanting date, presence/ absence of tomato, and year was not significant $(P=0.134)$; therefore, 2 years of data of dry biomass (DW) were pooled and analyzed together. Similarly, the interaction between the bell pepper transplanting date and the presence/absence of tomato was not significant $(P=0.439)$. When averaged across the presence or absence of tomato, the pepper biomass varied with the transplanting date $(P=0.002)$, with bell pepper transplanted on 7 Sept. (30-day interval) having the lowest DW compared with bell pepper transplanted on 8 Aug. (0-day interval) (Fig. 1A). Averaged across all planting dates, relay/intercropping bell pepper with tomato reduced the bell pepper biomass compared with that achieved with bell pepper alone $(P<0.0001)$ (Fig. 1B).

Pepper stem girth and internode length. The three-way interaction among the bell pepper transplanting date, presence/absence of tomato, and year was not significant $(P=$ 0.1818 ) for stem girth and internode length; therefore, data were pooled across years. Stem girth of bell pepper was affected by the presence of tomato $(P<0.001)$ and planting dates of bell pepper $(P=0.005)$ at 2 months (Fig. 2A and B). However, the interaction between the two factors was not significant $(P=0.107)$. The stem girth of bell pepper growing alone was significantly higher than that of bell pepper relay cropped with tomato (Fig. 2B), but the transplanting date had an inconsistent effect.

The interaction between the planting date of bell pepper and the presence/absence of tomato did not affect the bell pepper basal internode length at 1 month $(P=0.815)$ and 2 months $(P=0.759)$ after transplanting. Similarly, the main effect of the presence/ absence of tomato was not significant at 1 month $(P=0.303)$ and 2 months $(P=$ 0.691). However, the planting date of bell pepper significantly affected the pepper basal intermodal length at 1 month $(P=0.005)$. The basal internode length of pepper transplanted on 3 Sept. was significantly shorter than that of bell pepper transplanted on 8 Aug. when averaged across the presence or absence of the primary crop after 1 month. However, the basal internode length was the same for all planting dates at 2 months after planting.

Pepper heights. Bell pepper plant height data were subjected to a regression analysis. The slope (growth rate) was calculated for all bell pepper transplanted with and without 


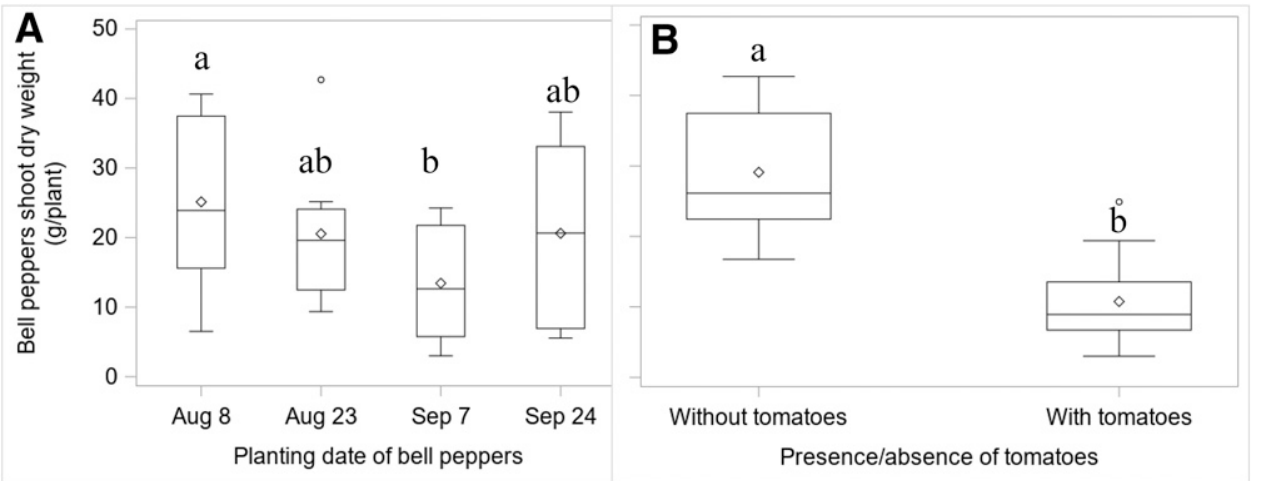

Fig. 1. Pepper plant dry weight \pm SE of (A) four planting dates (8 Aug., 23 Aug., 7 Sept., and 24 Sept.) of pepper and (B) when planted with and without tomato averaged across four replications grown in Balm, FL, in 2018 and 2019. Different letters indicate significant differences at $P<0.05$ using Tukey's adjusted means comparisons.

tomato at four different planting dates. The bell pepper growth rate was affected by the transplanting date $(P=0.001)$, but not by the presence of tomato $(P=0.976)$. Bell peppers transplanted with tomato generally were taller than bell peppers planted alone (Fig. 3). The growth rates of bell pepper transplanted on 8 and 23 Aug. were significantly greater than those of bell pepper transplanted at later transplanting dates.

Light measurements. In the morning, the presence of tomato did not cause $(P=0.481)$ shading on the east side. However, the intercepted light was significantly reduced (37\%) on bell pepper on the west side $(P=0.001)$ compared with bell pepper transplanted alone. In the afternoon, there was no difference in light interception on either side (east, $P=0.326$; west, $P=0.229$ ). In the evening, light interception on bell pepper was reduced by $55 \%$ on the east $(P \leq 0.001)$ and by $20 \%$ on the west $(P=0.036)$ compared with bell pepper grown without tomato.

Pepper yield. The interaction among year, transplanting date, and presence/absence of tomato was not significant $(P=0.134)$, and data from 2 years were pooled and analyzed together. Pepper yield did not vary with transplanting date and the presence/absence tomato $(P=0.060)$; therefore, only main effects are presented. Bell pepper yield was unaffected by the bell pepper transplanting date $(P=0.091)$ (Fig. 4A), but the presence of tomato $(P<0.001)$ significantly reduced the bell pepper yield. Bell pepper yield without tomato was $65 \%$ higher compared with yields with tomato (Fig. 4B).

Tomato biomass, height and yield. The pepper transplanting date had no effect on tomato biomass, yield $(P=0.420)$, or growth rate. The tomato yields were 51.4, 53.9, 44.6, 56.31 , and $42.4 \mathrm{Mg} \cdot \mathrm{ha}^{-1}$ when the bell peppers were not present and transplanted (relay cropped) on 8 Aug., 23 Aug., 7 Sept., and 24 Sept., respectively.

\section{Bell pepper with tomato as the secondary crop}

Pepper biomass, stem girth, internode length, heights, and yield. Pepper biomass was unaffected $(P=0.511)$ by the transplanting date of tomato. Stem girth of bell pepper did $\operatorname{not}(P=0.075)$ vary among treatments when tomato was transplanted at different dates. There were no differences in the growth rates of pepper plants when transplanted as the primary crop. Similarly, the interaction of year, transplanting date, and presence/absence of tomato was not significant $(P=0.609)$, and data were pooled and analyzed together. Bell pepper yield was affected by the tomato transplanting date $(P=0.024)$. Bell pepper yield was reduced when tomato was transplanted on the same day ( 8 Aug.) as the primary crop, but later planting dates had no effect on bell pepper yield (Fig. 5).

Light measurements. Tomato transplanted with bell pepper on the same day had significantly reduced light interception compared with tomato transplanted on 7 and 24 Sept. on the west side $(P=0.009)$ and east side $(P=0.008)$ in the morning and evening, respectively. Similarly, in the afternoon, the light interception was significantly $(P=$ 0.027 ) reduced on bell pepper by tomato on the east side only when tomato was transplanted on the same day compared with the last planting date of tomato.

Tomato biomass and height. The threeway interaction among year, planting date of tomato, and presence/presence of bell pepper $(P=0.653)$ was not significant for biomass. Similarly, the two-way interaction between the presence/absence of bell pepper and date of the planting of tomato $(P=0.283)$ was also not significant biomass. However, the tomato DW was significantly reduced when transplanted very late in the season (Fig. 6). Moreover, the DW of tomato transplanted with bell pepper was significantly $(P<$ $0.001)$ reduced compared to that of tomato grown alone.

The growth rate (slope) was significantly affected by the presence/absence of bell pepper $(P=0.003)$ and transplanting date of tomato $(P<0.001)$. However, the interaction between the two factors was not significant $(P=0.578)$. The growth rate of tomato transplanted on 7 Sept. was significantly higher than that of tomato transplanted on 23 Aug. (Fig. 7). However, the growth rate was higher for tomato transplanted with bell pepper compared with tomato transplanted alone.

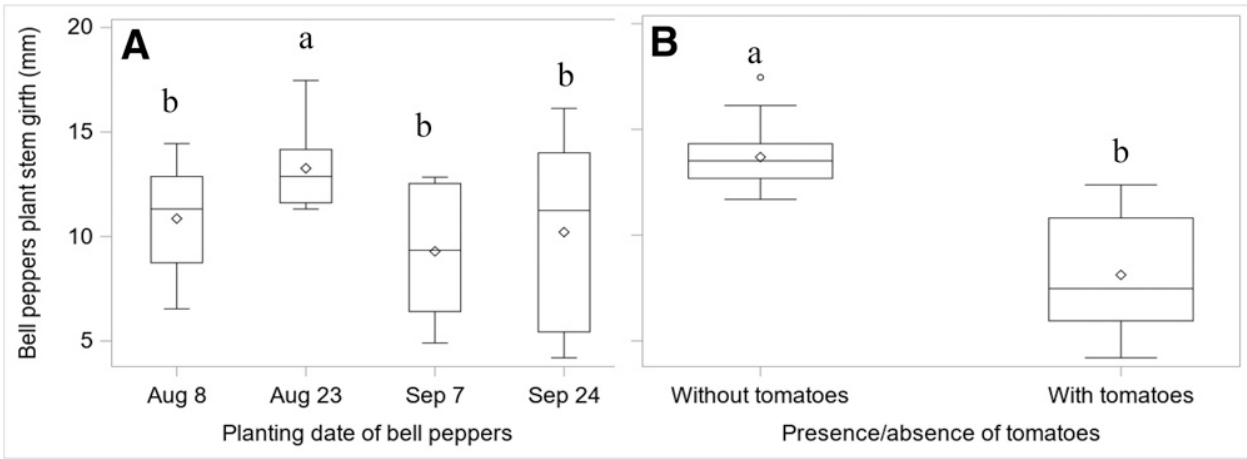

Fig. 2. Pepper plant stem girth \pm SE over (A) four planting dates of pepper and (B) when planted with and without tomato averaged across four replications grown in Balm, FL, in 2018 and 2019. Different letters signify differences at $P<0.05$ using Tukey's adjusted means comparisons. 


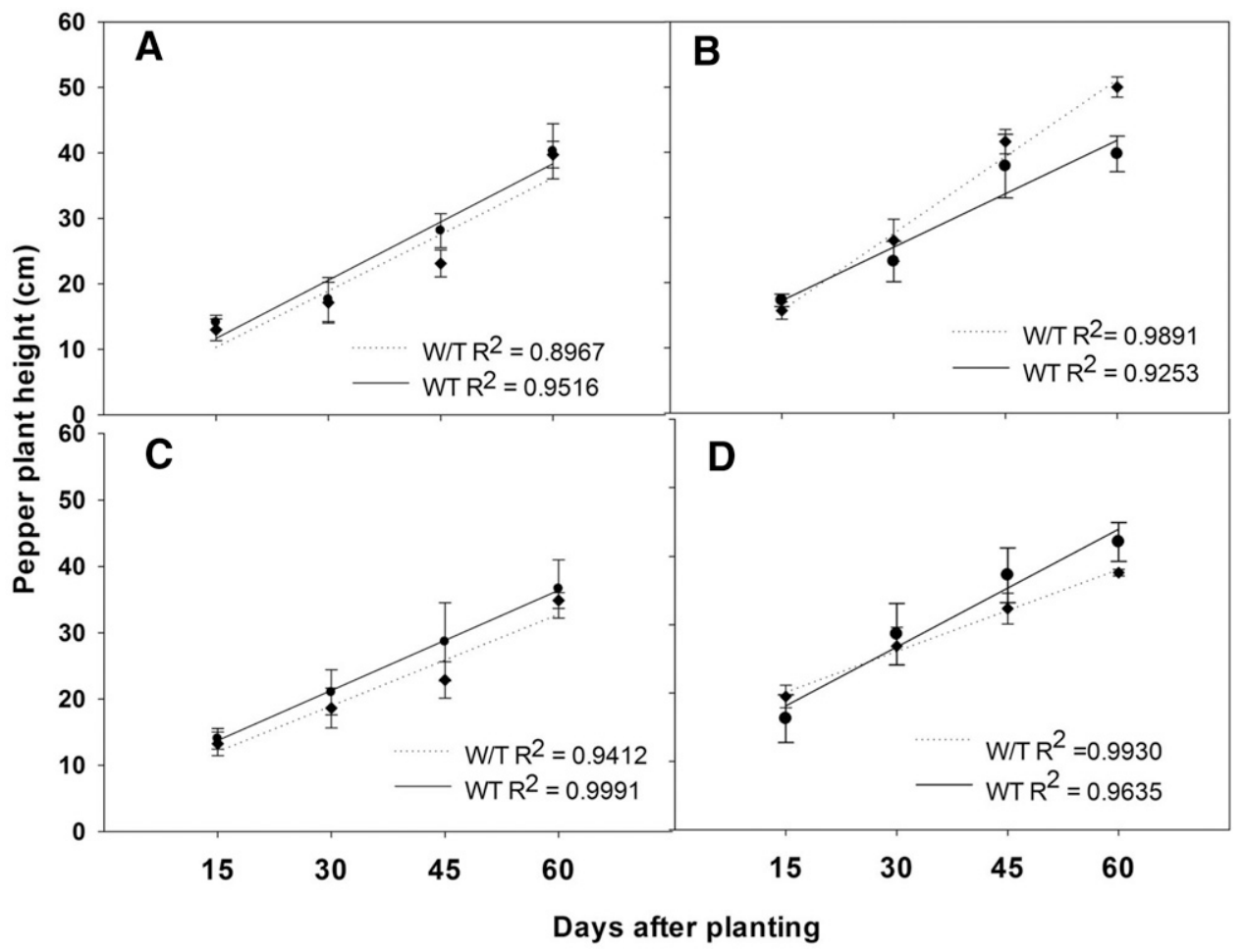

Fig. 3. Plant height \pm SE of peppers planted on (A) 8 Aug., (B) 23 Aug., (C) 7 Sept., and (D) 24 Sept. recorded at 15, 30, 45, and 60 d after planting when planted with and without tomatoes and averaged across four replications grown at Gulf Coast Research and Education Center (GCREC), Balm, FL, in 2018 and 2019. W/T represents the bell pepper plants without tomato. WP represents the bell peppers plants transplanted with tomato. Different letters signify differences at $P<0.05$ using Tukey's adjusted means comparisons.

Tomato yield. The three-way interaction among year, planting date of tomato, and presence/absence of bell pepper was not significant $(P=0.149)$. The interaction between the presence/absence of bell pepper and the date of the planting of tomato was significant $(P=0.006)$ for total tomato yield. Total tomato yield was only affected by the presence of pepper at the latest planting. The planting date only had an effect on yields when pepper was present. This was primarily attributable to reduced yields at the latest planting date (Table 1).

\section{Land equivalent ratio}

LER values of the tomato crop planted as the primary crop with bell pepper planted as a secondary crop on 8 Aug., 23 Aug., 7 Sept., and 24 Sept. were $1.3,1.0,1.1$, and 1.0, respectively. LER values of bell pepper planted as the primary crop with tomato planted as the secondary crop on 8 Aug., 23 Aug., 7 Sept., and 24 Sept. were 1.0, 1.4, 1.3, and 1.4, respectively. There were no differences among the LER values of different treatments.

\section{Discussion}

When the tomato crop was the primary crop and pepper was the secondary crop, bell pepper vegetative growth was reduced by the presence of tomato, with inconsistent effects of the planting date. However, the presence of pepper had no effect on the vegetative or reproductive growth of tomato. Wide row spacing $(122 \mathrm{~cm})$ is the standard in plasticulture tomato production to allow for equipment movement through the field. As a result, shading was not likely to cause significant effects on growth, even when relay cropping. The lack of difference in the bell pepper internode length among treatments suggested that tomato and bell pepper did not compete for light regardless of the transplanting date of the bell pepper. However, further research is needed to fully understand the effects of light quality when intercropping vegetables. The overall growth rate was lower for bell pepper transplanted in early to late September, which could have been caused by low air temperatures in November and December (Table 2). Criddle et al. (1997)

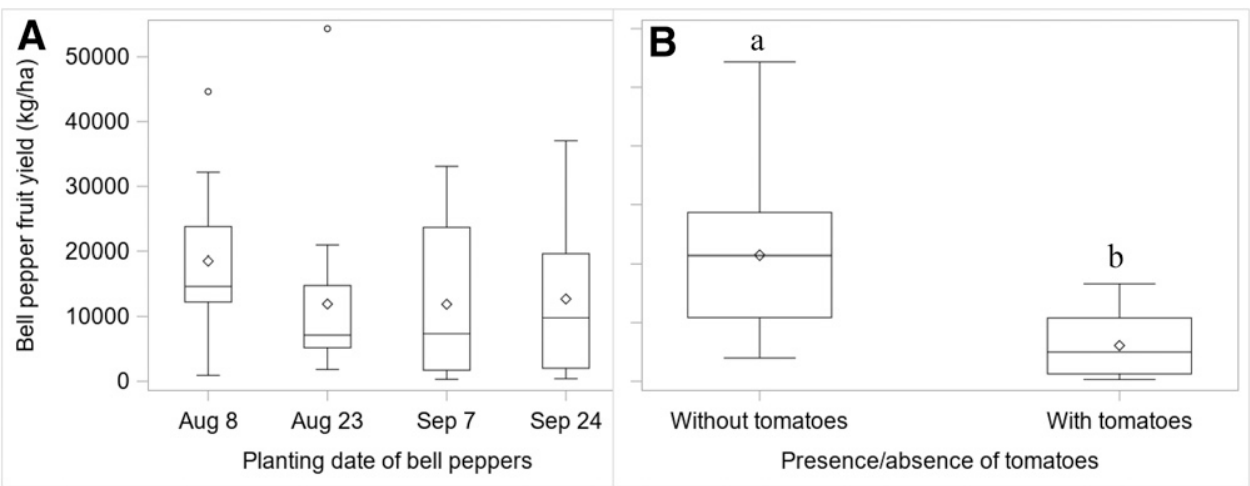

Fig. 4. Pepper fruit yields \pm SE over (A) four planting dates (8 Aug., 23 Aug., 7 Sept., and 24 Sept.) of pepper and (B) when planted with and without tomato averaged across four replications grown at Gulf Coast Research and Education Center (GCREC), Balm, FL, in 2018 and 2019. Different letters signify differences at $P<0.05$ using Tukey's adjusted means comparisons. 


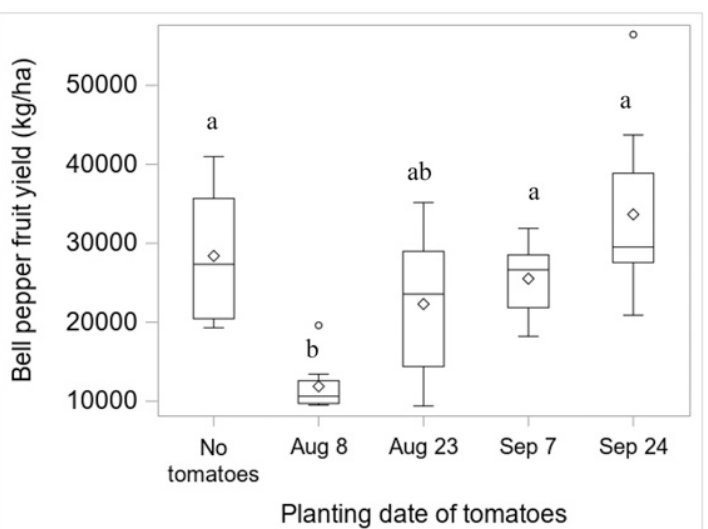

Fig. 5. Pepper fruit yields \pm SE when planted with tomato on four planting dates (8 Aug., 23 Aug., 7 Sept., and 24 Sept.) averaged across four replications grown at Gulf Coast Research and Education Center (GCREC), Balm, FL, in 2018 and 2019. Different letters signify differences at $P<0.05$ using Tukey's adjusted means comparisons.

explained that air temperatures less than $11.6^{\circ} \mathrm{C}$ could hinder the growth of plants belonging to the Solanaceae family.

Biomass, yield, and stem girth of bell pepper were greater when bell pepper was alone compared with those of bell pepper relay cropped with tomato. The higher SD represents that it is certain that there is a higher probability that bell pepper biomass was reduced by the presence of tomatoes. Competition between two crops may lead to resource scarcity, which affects the plant (root and shoot) vegetative growth and reproductive growth and reduces crop productivity (Farrior et al., 2013; Hegde, 1997). Differences observed between planting dates could have been caused by weather (temperature) conditions because the interaction between the planting date of bell pepper and the presence of tomato was not significant. However, pepper yield averaged across planting dates transplanted with tomato was lower than pepper yield averaged across planting dates transplanted without tomato. It is clear that weather associated with the transplanting date was an equally important factor as interspecific competition for belowground resources affecting yield and reduced tomato yield (Table 1). Filho et al. (2011) reported that tomato-lettuce intercropping resulted in lettuce yields that were significantly reduced when lettuce was transplanted with tomato after 30-d intervals compared with the lettuce transplanted on the same day as tomato and after $10 \mathrm{~d}$ (Filho et al., 2011).

Competition for resources could also reduce photosynthesis (Fichtner et al., 1995), effects on the net photosynthetic activity of bell pepper (Díaz-Pérez, 2013). However, the combined effect of shading and belowground competition for nutrients may explain the effects of the tomato plants on bell pepper vegetative growth and yields. Previous research at two locations in Ethiopia found contrasting results: total pepper yield was increased by $33 \%$ and $23 \%$ in two locations when intercropped with maize because the pepper transplanted alone had high pest pressure (Mitiku et al., 2014). The same study reported a reduction in pepper yield when intercropped with sweetpotato because of its robust growth behavior. Although tomato and bell pepper planting were temporally (transplanted at different times) distinguished, the rapid growth and large canopy of tomato could have affected the biomass and yields of bell pepper by competing for nutrients, light, but moderate shading is known to have no

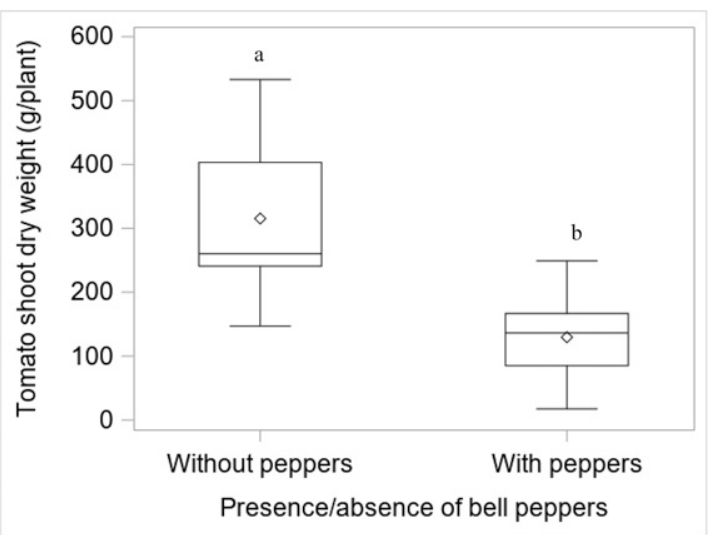

Fig. 6. Tomato plant dry weight when planted with and without pepper averaged across four replications grown at Gulf Coast Research and Education Center (GCREC), Balm, FL, in 2018 and 2019. Different letters signify differences at $P<0.05$ using Tukey's adjusted means comparisons.

and water, as proven by other studies (Ouma and Jeruto, 2010).

In Expt. 2, similar effects were noticed on vegetative (plant growth) and reproductive (yield) growth on the secondary crop (tomato), as in Expt. 1. When the tomato was transplanted as a secondary crop, tomato biomass, height, and yield were significantly reduced by the presence of bell pepper. This means that even if a crop with a more robust canopy is transplanted later as secondary crop, it is still affected by the crop already present. This would suggest that shading is not the only factor, and plants may be competing for nutrients as well as water. The tomato yield also indicates that when the primary crop is already established, the tomato yield is affected because of interspecific competition. The physiological reason could be that after fruit set, tomato fruit growth and development mainly depend on the transported metabolites, minerals and nutrients, and water from other organs of the plant (Bénard et al., 2015). Most metabolites are imported from photosynthetic leaves; therefore, low aboveground biomass would have an effect on fruit production of tomato. The high variability (SD) shows that there is a high probability of achieving better tomato biomass when planted without bell peppers.

Fertility management for intercropped tomato and bell pepper could be an essential aspect to study in future research. Establishment of the first crop is critical regardless of the size of the secondary crop. The current study is the first to demonstrate that regardless of canopy size, the presence of the initial crop can affect the secondary crop. Averaged over planting dates, tomato yield was reduced by $36 \%$ when transplanted with bell pepper. Prakash et al. (2004) reported that tomato relay cropped with maize had $12 \%$ to $32 \%$ reduced tomato yield compared with tomato transplanted alone. In addition, Buckelew et al. (2006) reported that a critical weed control period for tomato is 28 to $50 \mathrm{~d}$ after planting of tomato to avoid a $20 \%$ yield reduction, which further supports our theory that tomato yield was reduced when transplanted to an already-established bell pepper crop.

In the case of bell pepper transplanted as a primary crop, the yields were reduced only when tomato was transplanted on the same day as bell pepper because of the rapid growth behavior of tomato. Contradictory results indicating that Palmer amaranth could reduce the bell pepper fruit set if it emerges as early as 6 weeks after the transplanting of pepper have been reported (Norsworthy et al., 2008), suggesting that bell pepper is more sensitive to competition by weeds because of the enhanced nutrient uptake efficiency. The current results agree with those of the study of pepper transplanted in a glasshouse indicating reduced yields by $93 \%$ when nightshade emerged at the same time as pepper (Gonzalez Ponce et al., 1996). Unlike tomato, in Expt. 1, the competition duration had a significant effect on pepper. Although competition and yield reduction of the secondary crops were observed in both the experiments, the yield reduction was greater 


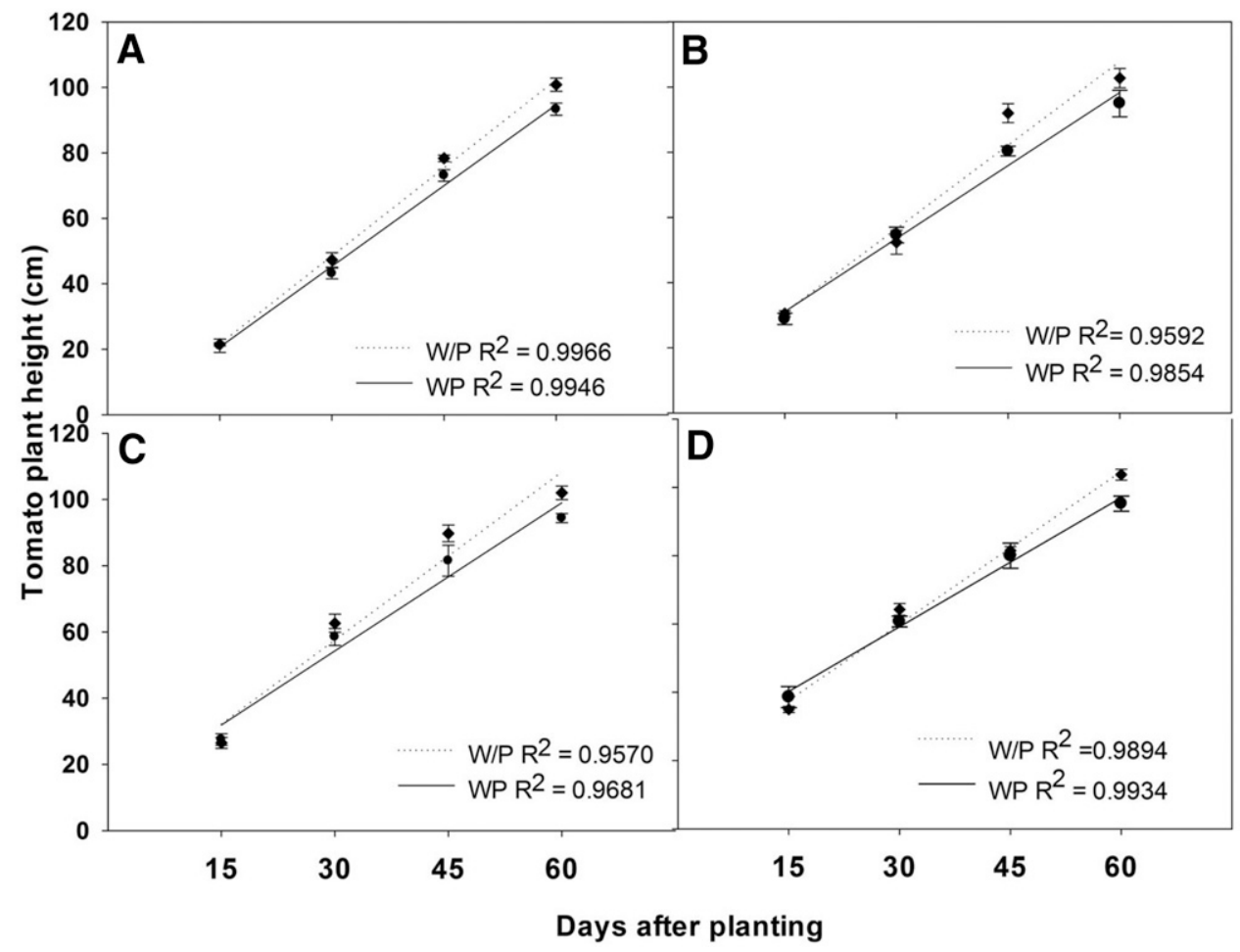

Fig. 7. Plant height of tomatoes planted on (A) 8 Aug., (B) 23 Aug., (C) 7 Sept., and (D) 24 Sept. recorded at 15, 30, 45, and 60 d after planting when planted with and without peppers and averaged across four replications grown at Gulf Coast Research and Education Center (GCREC), Balm, FL, in 2018 and 2019. The W/P represents the tomato plants without bell peppers and WP represents the tomato plants transplanted with bell peppers. Different letters signify differences at $P<0.05$ using Tukey's adjusted means comparisons.

Table 1. Total marketable and extra-large grade fruit yields of tomato planted on 8 Aug., 23 Aug., 7 Sept., and 8 Sept. averaged across four replications grown at Gulf Coast Research and Education Center, Balm, FL, in 2018 and 2019.

\begin{tabular}{lccccc}
\hline & \multicolumn{2}{c}{ Total marketable yield } & & \multicolumn{2}{c}{ Extra-large fruit yield } \\
\cline { 2 - 3 } \cline { 5 - 6 } & Without pepper & With pepper & & Without pepper & With pepper \\
\cline { 2 - 4 } Transplanting date & $58.5 \mathrm{a}$ & $43.4 \mathrm{ab}$ & & $48.3 \mathrm{a}$ & $35.5 \mathrm{ab}$ \\
8 Aug. & $48.6 \mathrm{ab}$ & $46.4 \mathrm{ab}$ & & $39.7 \mathrm{ab}$ & $35.0 \mathrm{ab}$ \\
23 Aug. & $58.8 \mathrm{a}$ & $28.4 \mathrm{bc}^{*}$ & & $40.7 \mathrm{ab}$ & $16.4 \mathrm{c}^{*}$ \\
7 Sept. & $51.7 \mathrm{a}$ & $20.8 \mathrm{c}^{*}$ & & $26.2 \mathrm{bc}$ & $8.9 \mathrm{c}$ \\
24 Sept. & &
\end{tabular}

${ }^{\mathrm{z}}$ Different lowercase letters show significant differences at $P<0.05$ using Tukey's adjusted means within the columns comparing different transplanting dates.

* Significant differences at $P<0.05$ using Tukey's adjusted means among the columns comparing yields of tomatoes planted with and without bell pepper.

for bell pepper $(65 \%)$ than for tomato $(36 \%)$, which means that tomato was more efficient and a greater competitor than bell pepper. Results of the experiments demonstrated that relay cropping is a viable option for vegetable

Table 2. Monthly average, minimum, and maximum temperatures $\left({ }^{\circ} \mathrm{C}\right)$ at Gulf Coast Research and Education Center, Balm, FL, in Fall 2019 and 2020

\begin{tabular}{llllllll}
\hline & \multicolumn{3}{c}{2018} & & \multicolumn{3}{c}{2019} \\
\cline { 2 - 4 } \cline { 5 - 6 } Month & Avg & Min & Max & & Avg & Min & Max \\
\hline August & 26.7 & 20.4 & 34.2 & & 26.9 & 21.4 & 34.2 \\
September & 27.1 & 22.2 & 34.5 & & 26.7 & 18.5 & 34.8 \\
October & 24.9 & 10.7 & 33.3 & & 25.5 & 18.7 & 33.2 \\
November & 20.5 & 3.0 & 31.5 & & 19.4 & 8.9 & 31.0 \\
December & 17.7 & 2.9 & 29.8 & & 18.6 & 4.3 & 28.6 \\
\hline
\end{tabular}

growers in Florida. Bell pepper perform better as the primary crop than as the secondary crop. Tomato is a high-revenue crop with robust growth and competitive behavior, and it is a viable option as a secondary crop. Expt. 2, which involved tomato transplanted as the secondary crop, used a more flexible system and relative yield loss was less for both the crops. The LER values for both experiments represent a yield advantage for relay cropping compared with monocropping.

The later planting dates (late August to September in both experiments) had no effect on the primary crop but affected the secondary crop yields. It is also important to consider that nonmarketable fruit and decaying plant tissue of the primary crop could harbor pests and diseases that affect the secondary crop, especially with late transplanting dates for the second crop. Therefore, the best practice is to adopt the mid-August to midSeptember planting dates.

In conclusion, tomato yield was unaffected by pepper when they were transplanted as the primary crop. Moreover, the tomato yield reduction was lesser compared with that of bell pepper when both the crops were transplanted as a secondary crop in the respective experiments. Therefore, we conclude that tomato performed better (higher yield) than bell pepper as a primary crop and as a secondary crop. Furthermore, the reduction in total yield and biomass of the tomato crop (when transplanted as a second crop) was lower compared with that of bell pepper (when transplanted as second crop). Therefore, we recommend planting bell pepper as the primary crop to gain a competitive advantage and transplanting the tomato 0 to 4 weeks later than bell pepper as a relay crop.

\section{Literature Cited}

Bénard, C., S. Bernillon, B. Biais, S. Osorio, M Maucourt, P. Ballias, C. Deborde, S. Colombié, C. Cabasson, D. Jacob, G. Vercambre, H. Gautier, D. Rolin, M. Génard, A.R. Fernie, Y. Gibon, and A. Moing. 2015. Metabolomic profiling in tomato reveals diel compositional changes in fruit affected by source-sink relationships. J. Expt. Bot. 66:3391-3404.

Biswas, T., Z. Guan, and F. Wu. 2017. An overview of the US bell pepper industry. Veg. Prod. Handb. Florida. Univ. Florida, IFAS Extension, Gainesville, FL.

Buckelew, J.K., D.W. Monks, K.M. Jennings, G.D. Hoyt, and R.F. Walls. 2006. Eastern 
black nightshade (Solanum ptycanthum) reproduction and interference in transplanted plasticulture tomato. Weed Sci. 54:490-495.

Criddle, R.S., B.N. Smith, and L.D. Hansen. 1997. A respiration based description of plant growth rate responses to temperature. Planta 201:441-445.

Díaz-Pérez, J.C. 2013. Bell pepper (Capsicum annum L.) crop as affected by shade level: Microenvironment, plant growth, leaf gas exchange, and leaf mineral nutrient concentration. HortScience 48:175-182.

Duval, J.R. 2005. Relay-intercropping does not reduce strawberry yield in an annual-hill production system. HortTechnology 15:907-908.

Farrior, C.E., D. Tilman, R. Dybzinski, P.B. Reich, S.A. Levin, and S.W. Pacala. 2013. Resource limitation in a competitive context determines complex plant responses to experimental resource additions. Ecology 94:2505-2517.

Fichtner, K., G.W. Koch, and H.A. Mooney. 1995. Photosynthesis, storage, and allocation, p. 133-146. In: E.-D. Schulze and M.M. Caldwell (eds.), Ecophysiology of photosynthesis. Springer, Berlin, Heidelberg.

Filho, A.B.C., B.L.A. Rezende, J.C. Barbosa, and L.C. Grangeiro. 2011. Agronomic efficiency of intercropping tomato and lettuce. An. Acad. Bras. Cienc. 83:1109-1119.

Freeman, J.H., E.J. Mcavoy, N.S. Boyd, K. Ramdas, M. Ozores-Hampton, H.A. Smith, J. Desaeger, J.W. Noling, and G.E. Vallad. 2017. Tomato production. Veg. Prod. Handb. Florida. Univ. Florida, IFAS Extension, Gainesville, FL.

Gaudin, A.C.M., K. Janovicek, R.C. Martin, and W. Deen. 2014. Approaches to optimizing nitrogen fertilization in a winter wheat-red clover (Trifolium pratense L.) relay cropping system. F. Crop. Res. 155:192-201.
Gonzalez Ponce, R., C. Zancada, M. Verdugo, and L. Salas. 1996. Plant height as a factor in competition between black nightshade and two horticultural crops (tomato and pepper). J. Hort. Sci. 71:453-460.

Guan, Z., T. Biswas, and F. Wu. 2017. The U.S tomato industry: An overview of production and trade. University of Florida, Gainesville, FL.

Hegde, D.M. 1997. Nutrient requirements of solanaceous vegetable crops, p. 58-70. In: R.A. Morris Shanhua (ed.). Managing soil fertility for intensive vegetable production systems in Asia. Asian Vegetable Research and Development Centre, Taiwan.

Jacques, S., R.K. Bacon, and L.D. Parsch. 1997. Comparison of single cropping, relay cropping and double cropping of soyabeans with wheat using cultivar blends. Exp. Agr. 33:477-486.

Karlidag, H. and E. Yildirim. 2009. Strawberry intercropping with vegetables for proper utilization of space and resources. J. Sustain. Agr. 33:107-116.

Letourneau, D.K., I. Armbrecht, B.S. Rivera, J.M Lerma, E.J. Carmona, M.C. Daza, S. Escobar, V. Galindo, C. Gutiérrez, and S.D. López. 2011. Does plant diversity benefit agroecosystems? A synthetic review. Ecol. Appl. 21:9-21.

Liu, G., G. Li, R. Yang, and L. Guo. 2018 Improving food safety in supply chain based on big data. E3S Web Conf. 53:03084.

Mitiku, A., A. Chala, and Y. Beyene. 2014. Effect of intercropping on aphid vectors and yield of pepper (Capsicum annum L.) in southern part of Ethiopia. Intl. J. Technol. Enhanc. Emerg. Eng. Res. 2:24-34.

Norsworthy, J.K., M.J. Oliveira, P. Jha, M. Malik, J.K. Buckelew, K.M. Jennings, and D.W. Monks. 2008. Palmer amaranth and large crabgrass growth with plasticulture-grown bell pepper. Weed Technol. 22:296-302.

Ouma, G. and P. Jeruto. 2010. Sustainable horticultural crop production through intercropping: The case of fruits and vegetable crops: A review. Agr. Biol. J. N. Amer. 1:1098-1105.

Prakash, V., A.K. Pandey, A.K. Srivastva, and H.S Gupta. 2004. Relay intercropping of hybrid tomato (Lycopersicon esculentum) in maize (Zea mays) under mid-hill condition of North-Western Himalayas. Indian J. Agr. Sci. 74:405-408.

Rosa-Schleich, J., J. Loos, O. Mußhoff, and T. Tscharntke. 2019. Ecological-economic tradeoffs of Diversified Farming Systems - A review. Ecol. Econ. 160:251-263.

Sandhu, R.K., N.S. Boyd, S. Sharpe, Z. Guan, Q. Qiu, T. Luo, and S. Agehara. 2020. Management of relay-cropped strawberry and eggplant to maximize yield and economic return. HortScience 55:1-7.

Sandhu, R.K., N.S. Boyd, L. Zotarelli, S. Agehara, and N. Peres. 2021. Effect of planting density on the yield and growth of intercropped tomatoes and peppers in Florida. HortScience 56:286-290.

Santos, B.M., C.E. Esmel, S. Slamova, and E.A. Golden. 2008. Optimum planting dates for intercropping cucumber, squash, and muskmelon with strawberry. HortTechnology 18:656-659.

Sargent, S.A. 1998. Tomato production guide for Florida: Harvest and handling 1. Coop. Ext. Serv. Inst. Food Agr. Sci. Univ. Florida. University of Florida, Gainesville, FL.

Theunissen, J. 1997. Intercropping in field vegetables as an approach to sustainable horticulture. Outlook Agr. 26:95-99.

USDA-NASS. 2016. Statistics of vegetables and melons. Agr. Stat. 2016:1-41. 